\title{
Aplicación de métodos de cocción saludables
}

\author{
Healthy cooking methods application \\ Alexia Soberanes Hernández ${ }^{a}$, Blanca Azalia López Hernández ${ }^{b}$, Atenas Loaiza Díaz ${ }^{c}$
}

\begin{abstract}
:
The meaning of cooking is to make raw food edible using heat. A cooking method is a set of steps required to transform food and its nutritional properties, food can be enriched or impoverished depending on the method used.
\end{abstract}

Keywords:

Cooking methods, heat, nutritional properties

\section{Resumen:}

El significado de cocción es hacer que un alimento crudo se vuelva comestible haciendo uso de calor. Un método de cocción es un conjunto de pasos que se requieren para transformar los alimentos y sus propiedades nutricionales, dependiendo de la técnica usada los alimentos pueden enriquecerse o empobrecerse.

Palabras Clave:

Métodos de cocción, calor, propiedades nutricionales

\section{Introducción}

Una dieta adecuada comienza con ingredientes saludables y de igual forma, la manera en la que los preparamos importa al momento de hacer una comida saludable 1. El objetivo de los métodos de cocción es obtener platillos que sean agradables y de fácil consumo para el organismo.

Al ingerir alimentos crudos como las frutas y hortalizas aprovechamos todos sus nutrientes. En productos como los cereales y legumbres la cocción es de suma importancia para personas que no pueden comer ni digerir en crudo 2.

Algunos métodos de preparación requieren de un excesivo uso de sodio, azúcar y grasas 1; la población no siempre piensa en cómo ciertos métodos de cocción afectan de manera negativa los alimentos, ya que el calor puede destruir una gran parte de los nutrientes que se encuentran en ellos, en caso contrario, en algunos otros el calor actúa como potencializador para dichos nutrientes.

\section{Desarrollo de la práctica:}

1. Objetivo general de la práctica:

Realizar una preparación culinaria, para conocer los diferentes métodos de cocción y su impacto en la gastronomía.

2. Instrumentos necesarios:

\footnotetext{
a Alumna del programa educativo de la Licenciatura en Gastronomía de la Universidad Autónoma del Estado de Hidalgo, Instituto de Ciencias Económico - Administrativas, https://orcid.org/0000-0002-4848-5145, Email: so270269@uaeh.edu.mx

${ }^{\mathrm{b}}$ Autor de Correspondencia, Profesora de Asignatura adscrita a la Licenciatura en Gastronomía de la Universidad Autónoma del Estado de Hidalgo, Instituto de Ciencias Económico - Administrativas, https://orcid.org/0000-0003-4238-1246, Email: blanca_lopez@uaeh.edu.mx ${ }^{c}$ Profesora de asignatura adscrita a la Licenciatura en Gastronomía de la Universidad Autónoma del Estado de Hidalgo, Instituto de Ciencias Económico - Administrativas, https://orcid.org/0000-0001-5521-4725, Email: atenas_loaiza@uaeh.edu.mx 
Licuadora, tabla, cuchillo chef, coludo, pala de madera, bowl, zaranda, asador.

3. Insumos requeridos:

\begin{tabular}{|c|c|}
\hline INGREDIENTES & CANTIDAD \\
\hline Huauchinango & $0.200 \mathrm{~kg}$ \\
\hline Diente de ajo & $1.00 \mathrm{pieza}$ \\
\hline Cebolla blanca & $0.010 \mathrm{~kg}$ \\
\hline Chile guajillo & $0.010 \mathrm{~kg}$ \\
\hline Sal & $0.001 \mathrm{~kg}$ \\
\hline Pimienta & $0.001 \mathrm{~kg}$ \\
\hline Jugo de naranja & $0.009 \mathrm{I}$ \\
\hline Jugo de limón & $0.015 \mathrm{I}$ \\
\hline Salsa huichol & $0.050 \mathrm{I}$ \\
\hline
\end{tabular}

Tabla 1. Elaboración propia

\section{Preparación:}

1. Pesar y lavar todos los ingredientes.

2. Preparar un adobo con ajo, cebolla, chile guajillo, sal, pimienta, jugo de naranja, jugo de limón y salsa huichol; cocinar hasta reducir, licuar y reservar.

3. Sazonar el huachinango con sal y pimienta. Marinarlo en el adobo y colocarlo en una zaranda.

4. Cocinar a la leña 2 minutos por lado.

5. Servir.

\section{Conclusiones}

Los métodos de cocción de los alimentos pueden modificar sus propiedades nutricionales, debemos tomar en consideración el tiempo de cocción al que exponemos los productos, ya que puede afectar estas propiedades 3 . Para poder entender los métodos de cocción debemos entender primero las formas en las que se conduce el calor y los efectos que conlleva.

\section{Referencias}

[1]. Government of Canada. (2020). Healthy Cooking Methods. Canada's Food Guide. Recuperado de https://food-guide.canada.ca/en/tips-forhealthy-eating/healthy-cooking-methods/

[2]. Kathyn, S. \& Greatist.com. (2013,02-01). The healthiest Cooking Methods Explained. Time. Recuperado de https://healthland.time.com/2013/02/01/the-healthiest-cooking-methodsexplained/

[3]. World Cancer Research Fund. (n.d.). How to cook healthily. World Cancer Research Fund. Recuperado de https://www.wcrfuk.org/uk/recipes/how-cook-healthily 